\title{
Meaning and Context
}

\author{
Bettina Reiter \\ Private Praxis, Vienna, Austria
}

'MACs' are not only stylish computers or old-fashioned raincoats, but recently they have also invaded the perennial discussion in medicine about 'what is the healing in the healing act?'. In the medical world, 'MAC' stands for 'meaning and context' and as such is more or less the updated version of the good old placebo effect (see for instance Jonas' [1] definition of placebo effect: '1) the effect of any therapeutic technique that has no objectively determinable action on the illness for which it is prescribed; 2) the patient's innate healing, defense and survival processes that are elicited through the meaning and context of a treatment').

Following the twisted discussion around the placebo effect, its virtues, its pitfalls, its definitions and, most of all, its causes always makes me wonder why literally no one pays attention to some old and quite well-known facts about the powerful drug called 'doctor'. The phrase 'the drug doctor' (das Heilmittel Arzt) was introduced by the Hungarian psychoanalyst Michael Balint [2], who was concerned about the patient-doctor relationship. This in itself is nothing special because everybody is concerned about the doctor-patient relationship and everybody is likely to claim its importance. But that's about it usually.

It is quite impossible to find specifications about what makes the doctor a 'special drug' other than the usual redundant keywords like 'empathy' and 'time' or even more ideology-driven terms like 'humanism' or 'whole person approach'. As if all you have to do in order to be a good healer is to sit and nod emphatically and your patients would become better more or less automatically. This of course is not the case, but it is not completely untrue, either.

Balint has devoted much of his scientific work to the research of what, on the one hand, makes doctors understand their patients' needs and, on the other hand, makes patients feel being understood by their doctors. In his notion, a therapeutic dialogue can be established only if the doctor is capable of grasping the message his patient gives him. And a therapeutic dialogue needs to be established if the medical procedures are meant to work. This is where 'meaning and context' come in.
Generally, doctors are not very good in understanding their patients because they do not get their messages. But this, of course, is only one side of the medal. On the reverse side, we see a patient who conveys his message packed in a symptom and who feels panicked, aching, suffering but also maybe demanding and reproachful.

So we have 2 protagonists staring at something called symptom and looking for solutions at - what Balint and with him the whole discipline called psychoanalysis thinks to be the wrong place.

The medical thinking shrinks away from persons and looks at body symptoms, the suffering person also shrinks away from himself, so to speak, and says something like: 'Do something here, doctor - but don't look at me, look at my symptom. I cannot bear to look at myself - that's why I have a symptom. We certainly can agree on that, can we not?' And usually we - the doctors - can.

Medicine is a very potent system of avoidance, and it complies in this respect very well with the patients' overt approach to his situation: 'Do something about my symptom, not about me!'

Only that the patient has every right in the world to do so: he is ill, he has a symptom, is suffering and needs to be taken care of! This is not so easy on the doctor's side, he should know better and be alert to the packed messages that are delivered in the same parcel as the migraine, the irritable bowel, the low back pain, the cancer or the heart condition, the chronic prostatitis - you name it, you have it.

Now what are these mysterious messages? Unconscious feelings, inner conflicts, character traits that dig their way into the body, models of interaction that have been always with the person and ensured a stable enough balance that now the symptom is witness to that - breaks down and there is no backup system in the person's make-up. Much of the suffering in illnesses is due to the breakdown of what Balint might have called the defence system - and of course he would have borrowed the term from Freud [3].

\section{KARGER \\ Fax +497614520714 \\ Information@Karger.de}

www.karger.com (c) 2011 S. Karger GmbH, Freiburg

1661-4119/11/0186-0312\$38.00/0

Accessible online at:

www.karger.com/fok
Dr. med. Bettina Reiter

Beckgasse 18

1130 Wien, Austria

Tel. +4318794265

praxis@reiter.priv.at 
In this respect, a successful healing always comes along with a reestablishment of an intact defence system, not always in the same way and on the same level as before the illness, but there still has to be a new balance - the outer sign of which is that the doctor is not needed anymore.

Psychoanalysis has a theory for what happens between doctors and patients; this is because psychoanalysis has a theory about people in general. This special theory differs insofar from others as it is specifically tailored to tackle the non-overt phenomena like unconscious wishes, drives, their vicissitudes (as Freud elegantly puts it, the fate of body needs that become psychic - though we do not know how on a biological level) and the defences against these wishes. Psychoanalysis is not primarily interested in behaviour, but in what makes a person behave like he does.

As the theory was developed from the clinic bottom-up, it has all the strengths of a practical theory - and of course its weaknesses, too. For the moment being and the argument here, we stick to the strength that lies, in my opinion, in the one notion that would, if medicine could pick it up in a productive manner, give a kick to the placebo discussion and especially to the 'meaning and context' phrase.

One of the several ground-breaking ideas by Freud is the concept of 'transference' - by which a psychoanalyst means (nowadays) that the patient puts all his unconscious objectrelated wishes into the doctor (the analyst for that matter), which results in a relationship between the 2 protagonists that is - from the patients' side of view - modelled after the first and decisive relationship experiences. This not only applies on the factual reality of these relationships, but equally, if not even more important, to the unconscious wishes and needs that define, regulate and even determinate the way in which a person relates to other people and life in general.
Transference from the patient is met with the 'countertransference' from the doctor, by which we mean the ensemble of attitudes towards the patient - the known and the unknown ones. It has become a tool in modern psychoanalysis and serves well to detect the packed messages of the patient. It can be trained.

The doctor who knows something about his own countertransference to whatever the patient brings is in a better position to heal than the one who has no idea about that and must stick to the symptom side or retreat to a rather empty 'empathy' position.

When we ask about 'MACs' in medicine we might think about this tool 'transference/counter-transference' that lies right at hand for quite a long time now, and we might think about the discipline that has accumulated a lot of knowledge about the hidden sides of the contact between a healer and someone who wants to be healed. Although there are a lot of methodological questions to be solved on the way to rend the concept operative in a research setting in medicine, I think it is not only worthwhile looking into it, but really necessary. As far as I know, there is no other specific concept around that claims to fit to the questions at hand when it comes to placebo or 'MACs'.

What in a clinical trial is called 'unspecific effect' or placebo might as well be a highly specific transference effect, and we simply do not know anything about it.

\section{Literatur}

1 Jonas WB (ed): Mosby's Dictionary of Complementary and Alternative Medicine. St. Louis, Elsevier, 2005.

2 Balint M: The Doctor, His Patient and The Illness. London, Pitman Medical, 1957.

3 Freud S: Das Ich und das Es. Gesammelte Werke, Band 13. Frankfurt/M., Fischer, 1947, pp 237-289. 